\title{
Sortilin Deficiency Reduces Ductular Reaction, Hepatocyte Apoptosis, and Liver Fibrosis in Cholestatic-Induced Liver Injury
}

Einav Hubel, ${ }^{*}$ Ashish Saroha, ${ }^{\dagger}$ Woo-Jae Park, ${ }^{\ddagger}$ Yael Pewzner-Jung, ${ }^{\dagger}$ Elise G. Lavoie, ${ }^{\S}$ Anthony H. Futerman, ${ }^{\dagger}$ Rafael Bruck, * Sigal Fishman, ${ }^{*}$ Jonathan A. Dranoff, ${ }^{\S}$ Oren Shibolet, ${ }^{*}$ and Isabel Zvibel*

From the Research Center for Digestive Tract and Liver Diseases, * Tel Aviv Sourasky Medical Center and the Sackler Faculty of Medicine, Tel Aviv University, Tel Aviv, Israel; the Department of Biological Chemistry, ${ }^{\dagger}$ Weizmann Institute of Science, Rehovot, Israel; the Department of Biochemistry, ${ }^{\ddagger}$ School of Medicine, Gachon University, Incheon, Republic of Korea; and the Division of Gastroenterology and Hepatology, ${ }^{\S}$ University of Arkansas for Medical Sciences, Little Rock, Arkansas

Accepted for publication September 1, 2016.

Address correspondence to Isabel Zvibel, Ph.D., Research Center for Digestive Tract and Liver Diseases, Tel Aviv Sourasky Medical Center, Weizman 6, Tel Aviv 64239, Israel. E-mail: isab@tlvmc. gov.il.

\begin{abstract}
Sortilin, a member of the vacuolar protein sorting 10 domain receptor family, traffics newly synthesized proteins from the trans-Golgi network to secretory pathways, endosomes, and cell surface. Sortilintrafficked molecules, including IL- 6 and acid sphingomyelinase (aSMase), mediate cholangiocyte proliferation and liver inflammation, hepatic stellate cell activation, hepatocyte apoptosis, and fibrosis. Based on these sortilin-regulated functions, we investigated its role in biliary damage leading to hepatocellular injury and fibrosis. Sortilin ${ }^{-1-}$ mice displayed impaired inflammation and ductular reaction 3 days after bile duct ligation (BDL), as demonstrated by reduced cholangiocyte proliferation and activation and reduced serum IL-6. Interestingly, liver fibrosis was reduced in Sortilin ${ }^{-/-}$mice after both BDL and carbon tetrachloride treatment, in line with attenuated in vitro activation of Sortilin ${ }^{-1-}$ hepatic stellate cells. Sortilin ${ }^{-1-}$ hepatic aSMase activity was reduced in the BDL and carbon tetrachloride models and accompanied by reduced in vivo hepatocyte apoptosis. In addition, wild type (WT), but not Sortilin ${ }^{-1-}$ hepatocytes, had increased aSMase-dependent susceptibility to bile acid-induced apoptosis in vitro. Mechanistically, short-term IL-6 neutralization in bile duct-ligated WT mice decreased hepatic inflammation and reactive cholangiocyte-derived cytokines and chemokines, without affecting fibrosis, whereas pharmacological inhibition of aSMase activity was not sufficient to attenuate hepatic fibrosis. Only combined IL- 6 and aSMase inhibition significantly reduced fibrosis in bile ductligated WT mice. We conclude that sortilin regulates cholestatic liver damage and fibrosis via effects on both aSMase activity and serum IL-6. (Am J Pathol 2017, 187: 122-133; http://dx.doi.org/10.1016/ j.ajpath.2016.09.005)
\end{abstract}

Hepatic fibrosis and cirrhosis are the final outcomes of many types of liver injuries, including viral hepatitis, cholestasis, and alcoholic and nonalcoholic steatohepatitis. These different types of liver injuries are accompanied by oxidative stress, hepatocyte or cholangiocyte apoptosis, and inflammation, leading to deposition of extracellular matrix, particularly collagen type I, produced by myofibroblasts, which are derived mainly from activation of hepatic stellate cells (HSCs) and in some cases from activation of portal fibroblasts. ${ }^{1-5}$

Cholestatic liver injury, predisposing to biliary fibrosis and cirrhosis, can be caused by various pathologies that impair bile flow and result in accumulation of bile in the liver. These include genetic defects, structural/mechanical obstruction of bile ducts impairing bile flow, toxins, and dysregulated function of the immune system. In the early stages of cholestatic injury, there is an increased number of proliferating bile ducts, myofibroblast activation, and an

Supported by the Israel Science Foundation grants $881 / 09$ (I.Z.) and 970/12 (O.S.).

O.S. and I.Z. contributed equally as senior authors.

Disclosures: None declared. 
influx of inflammatory cells, a phenomenon termed ductular reaction. ${ }^{3,6,7}$ Reactive cholangiocytes, which are typical of the ductular reaction, express increased levels of cytokines [tumor necrosis factor (TNF)- $\alpha$, IL-1 $\beta$, IL-8, IL-6, and interferon- $\gamma$ ], chemokines (chemokine ligand 2, CXCL1, and CXCL2), autocrine mitogenic growth factors (progranulin and nerve growth factor), adhesion molecules, and fibrogenic molecules; these cells also have features of neuroendocrine cells. ${ }^{3,6,7}$ The factors secreted by reactive cholangiocytes have important roles in inflammation and cross talk with the surrounding portal fibroblasts, inducing their differentiation into myofibroblasts. ${ }^{8-10}$

Sortilin is a newly identified member of the vacuolar protein sorting 10 family and can act both as a coreceptor and as a trafficking molecule in the trans-Golgi network. ${ }^{11}$ As a trafficking molecule, sortilin directs several newly synthesized molecules to the endosomal compartments, to secretory vesicles, and to the cell surface. ${ }^{11}$ Recently, sortilin was shown to regulate secretion of cytokines from immune cells, specifically secretion of interferon $\gamma$ from T cells ${ }^{12}$ and IL-6 from macrophages, and mice reconstituted with $\mathrm{Sortilin}^{-1-}$ bone marrow displayed reduced circulating levels of IL- 6 . $^{13}$ IL-6 is a central inflammatory cytokine, induced during a variety of liver injuries. Cholestatic injury to bile ducts rapidly induces expression and secretion of IL-6 in both cholangiocytes and immune cells around bile ducts, where IL-6 participates in proliferation of cholangiocytes and in processes of repair and barrier protection of the ducts. ${ }^{14-16}$ However, the role of IL-6 is somewhat controversial, with some studies finding a protective role and others a deleterious role for IL-6 in cholestatic injury. ${ }^{17-21}$

Another protein trafficked by sortilin is acid sphingomyelinase (aSMase), ${ }^{22-24}$ which catalyzes the turnover of sphingomyelin to ceramide, thereby regulating cellular levels of ceramide. ${ }^{25}$ Ceramide is a major signal transduction molecule involved in apoptosis, ${ }^{26}$ and hepatocytes from Asmase ${ }^{-1-}$ mice display reduced apoptosis in response to TNF- $\alpha .{ }^{27}$ Moreover, in vivo studies revealed the specific involvement of Asmase in cholestatic injury, whereas heterozygous Asmase ${ }^{+/-}$mice show reduced hepatic fibrosis after bile duct ligation (BDL) or carbon tetrachloride treatment. ${ }^{28,29}$ Our previous studies have shown that Sortilin ${ }^{-1-}$ mice had reduced aSMase activity under a high-fat diet regimen, and their reduced aSMase activity improved their insulin signaling, which is inhibited by ceramide. ${ }^{30}$

Based on the studies above, we hypothesized that sortilin may increase trafficking of aSMase and therefore reduce resistance of hepatocytes to external apoptotic signals, potentially enhancing pathways leading to fibrosis. In addition, we also suggest that elevated circulating serum IL-6, regulated by sortilin, may result in increased reactive cholangiocytes and inflammation in liver injury-induced fibrosis. Therefore, in the present study, we used Sortilin ${ }^{-1-}$ mice to investigate the role of sortilin in cholestatic-induced inflammation, ductular reaction, and fibrosis via regulation of aSMase activity and IL-6 levels.

\section{Materials and Methods}

\section{Animals}

C57Bl/6 mice (Harlan, Jerusalem, Israel) [wild type (WT)] and Sortilin ${ }^{-1-}$ mice, obtained by introduction of the neo gene into exon 14 and the following intron of the sortilin gene $^{31}$ (a kind gift of Prof. Anders Nykjaer, The Lundbeck Foundation Research Center MIND, Aarhus University, Aarhus, Denmark), were maintained in the animal facility of the Tel Aviv Sourasky Medical Center (Tel Aviv, Israel) on a standard rodent chow diet with 12-hour light cycles. All experiments were approved by the Tel Aviv Sourasky Medical Center Animal Use and Care Committee.

\section{In Vivo Induction of Fibrosis by BDL and by Carbon Tetrachloride}

WT and Sortilin ${ }^{-1-}$ mice were anesthesized with xylazil and ketamine, their abdomen opened, and two ligatures (one near the pancreas, the other near the liver) were performed on the common bile duct using silk thread (5.0) and the common bile duct between them was cut. Mice were sacrificed 3, 7, 14, and 21 days later.

For fibrosis induction by carbon tetrachloride, mice received i.p. injections of carbon tetrachloride dissolved in olive oil, carbon tetrachloride, $0.85 \mu \mathrm{L} / \mathrm{g}$ body weight, twice a week for a total of 4 weeks, and were sacrificed 48 hours after the last carbon tetrachloride injection.

For aSMase inhibition in vivo, WT mice subjected to BDL received amitriptyline i.p. every day $(2.5 \mathrm{mg} / \mathrm{kg}$ body weight) for 7 or 14 days. For inhibition of IL-6, WT mice subjected to BDL received daily i.p. injection of $1 \mu \mathrm{g} /$ mouse of an anti-IL-6 neutralizing antibody (clone MAB406; R\&D Systems, Minneapolis, MN) for a total of 3 days.

\section{Determination of Fibrosis by Quantitation of Sirius Red Staining}

Midsections of the left lobes of the livers were processed for light microscopy by fixing the specimens in a $5 \%$ neutral formol solution, embedding the specimens in paraffin, making sections ( $5 \mu \mathrm{m}$ thick), and staining the sections with Sirius Red to detect fibrillar collagen. ${ }^{32}$ The Sirius Red-positive areas in at least 20 sections were calculated as percentages from the same size area in all micrographs using open source ImageJ software version 1.49t (NIH, Bethesda, MD).

\section{Collagen Detection by Hydroxyproline Quantitation Assay}

Liver fibrosis was also quantitated using a hydroxyproline assay kit (Sigma, St. Louis, MO), according to the manufacturer's instructions. 


\section{Murine HSC Isolation and Culture}

Livers of WT or Sortilin ${ }^{-1-}$ mice were minced and incubated with $50 \mathrm{~mL}$ of Gey's Balanced Salt Solution containing $1 \mathrm{mg} / \mathrm{mL}$ collagenase, $1 \mathrm{mg} / \mathrm{mL}$ pronase, $20 \mu \mathrm{g} / \mathrm{mL}$ DNase I (Sigma), and $0.027 \% \mathrm{CaCl}_{2}$ for 45 minutes at $37^{\circ} \mathrm{C}$ with $200 \mathrm{rpm}$ shaking. The digested tissue was filtered through a sterile $150-\mu \mathrm{m}$ mesh, cells were centrifuged at $870 \times g$ for 7 minutes, and HSCs were isolated on a $10 \%$ Nycodenz gradient centrifuged at $1400 \times g$ for 20 minutes. Cells were cultured in Dulbecco's modified Eagle's medium supplemented with $10 \%$ fetal calf serum, $100 \mu \mathrm{g} / \mathrm{mL}$ penicillin, and $100 \mu \mathrm{g} / \mathrm{mL}$ streptomycin.

\section{Primary Murine Hepatocyte Isolation and Culture}

Hepatocytes from WT and Sortilin ${ }^{-1-}$ mice were isolated as previously described. ${ }^{30}$

\section{Immunohistochemistry}

Paraffin liver sections were deparaffinized and stained with antibodies to Ki-67 (SolA15; eBiosciences, San Diego, CA) and antibodies to Ly6G (clone 1A8; Biolegend, San Diego, CA).

\section{aSMase Activity Assays}

aSMase activity from liver extracts was assessed as described. ${ }^{30,33}$ Briefly, livers were homogenized in sodium acetate buffer $(50 \mathrm{mmol} / \mathrm{L}$ sodium acetate, $\mathrm{pH} 4.5)$ containing protease inhibitors (Sigma). Protein was determined using the BCA Protein Assay Kit (Thermo Fisher Scientific, Waltham, MA), and 40 to $50 \mu \mathrm{g}$ of protein was used for the assay. The assay was initiated with $1 \mathrm{nmol} \mathrm{C}_{6}-\mathrm{NBD}-\mathrm{SM}$ (Avanti Polar Lipid, Alabaster, AL) in $50 \mathrm{mmol} / \mathrm{L}$ sodium acetate buffer, $\mathrm{pH} 4.5,37^{\circ} \mathrm{C}$, for 15 to 30 minutes, and stopped by the addition of chloroform/methanol $(1: 2 ; \mathrm{v} / \mathrm{v})$. Lipids were separated by thin layer chromatography using chloroform/methanol/9.8 mmol/L $\mathrm{CaCl}_{2}(60: 35: 8 ; \mathrm{v} / \mathrm{v} / \mathrm{v})$. Thin layer chromatography plates were scanned by Typhon (GE Life Sciences, Uppsala, Sweden) and quantified by the Image Quant program (GE Life Sciences).

\section{Apoptosis Assays in Vivo and in Vitro}

Apoptosis on liver paraffin sections was determined using the terminal deoxynucleotidyl transferase-mediated dUTP nick-end labeling assay, according to the manufacturer's instructions (Promega, Madison, WI). WT and Sortilin ${ }^{-/}$ hepatocytes were isolated, as described, ${ }^{30}$ and plated on collagen I-coated plates and in serum-free, hormonally defined medium. The next day, cells were treated for 8 hours with $200 \mu \mathrm{mol} / \mathrm{L}$ taurocholic acid (TCA) in the presence or absence of $10 \mu \mathrm{mol} / \mathrm{L}$ amitriptyline. Cells were fixed with 4\% paraformaldehyde for 20 minutes at room temperature and stained with the terminal deoxynucleotidyl transferasemediated dUTP nick-end labeling kit, according to the manufacturer's instructions. Nuclei were stained with DAPI contained in the mounting medium. Apoptotic nuclei were visualized using a confocal Zeiss microscope (Zeiss, Oberkochen, Germany).

\section{IL-6 Detection}

Serum IL-6 was detected using an enzyme-linked immunosorbent assay kit for murine IL-6 (Biolegend, BLG431304). The thiobarbituric acid reactive substances assay was performed using a kit from Cayman (Cay-10009055; Ann Arbor, MI).

\section{Immunoblotting}

Proteins from HSCs were extracted by homogenization in ice-cold radioimmunoprecipitation assay buffer (phosphatebuffered saline, $1 \%$ NP40, $0.5 \%$ sodium deoxycholate, $0.1 \%$ SDS, $1 \mathrm{mmol} / \mathrm{L}$ phenylmethylsulfonyl fluoride, $5 \mu \mathrm{g} / \mathrm{mL}$ aprotinin, $10 \mu \mathrm{g} / \mathrm{mL}$ leupeptin, $1 \mu \mathrm{g} / \mathrm{mL}$ pepstatin $\mathrm{A}$, and a phosphatase inhibitor cocktail). Homogenates were centrifuged for 25 minutes at $13,000 \times g$, supernatants were collected, and protein concentration was determined. Proteins were separated by SDS-PAGE, blotted onto nitrocellulose, and blocked for 1 hour at room temperature in 5\% skim milk powder. Blots were incubated overnight at $4{ }^{\circ} \mathrm{C}$ with antibodies to collagen I (AB765P, 1:500; Millipore, Billerica, MA), $\alpha$-smooth muscle actin (1:1000), plateletderived growth factor receptor $\beta$ (1:1000) (Santa Cruz Biotechnologies, Santa Cruz, CA), and cytokeratin 19 (1:5000) (Abcam, Cambridge, UK), an antibody to housekeeping protein p97 and to $\alpha$-tubulin (Sigma), then incubated with horseradish peroxidase-conjugated secondary antibody and subjected to chemiluminescent detection.

\section{Real-Time RT-PCR}

Total RNA was extracted using TriReagent (Sigma) and reverse transcribed using the High Capacity cDNA RT kit (Thermo Fisher Scientific). Real-time RT-PCR was performed with the Fast SYBR Green Master Mix (Thermo Fisher Scientific) in the Corbett rotor light cycler. Gene expression for each gene was normalized to the expression of housekeeping gene Rplpo. Results are presented as means \pm SEM. Murine primers used were as follows (forward and reverse, respectively): Collagen $1 \alpha 1,5^{\prime}$-GAGAGCATGACCGATGGATT$3^{\prime}$ and 5'-CCTTCTTGAGGTTGCCAGTC-3'; Cxcll, 5'GCTGGGATTCACCTCAAGAA- ${ }^{\prime}$ and $5^{\prime}$-AAG-GGAGCTTCAGGGTCAAG- $3^{\prime}$; $C x c l 2,5^{\prime}$-AGTGAACTGCGCTGTCAATG- $3^{\prime}$ and $5^{\prime}$-TCAGGGTCAAGGCAAACTT- $3^{\prime} ; \mathrm{Il}-6$, $5^{\prime}$-CCGGAGAGGAGACTTCACAG- $3^{\prime}$ and $5^{\prime}$-TTCTGCAAGTGCATCATCGT-3'; $\quad C c l 2, \quad 5^{\prime}$-AGGTCCCTGTCATGCTTCTG-3' and 5'-GCTGCTGGTGATCCTCTTGT-3'; $N g f$, 5'-CATGGGGGAGTTCTCAGTGT-3' and 5'-GCA- 
CCCACTCTCAACAGGAT-3'; Prgn, 5'-AAGGAGGTGAAGTGCGACAT- $3^{\prime}$ and $5^{\prime}$-TCGCAGGTTCCTTTCTCTGT$3^{\prime}$; Rplpo, 5'-CAACCCAGCTCTGGAGAAAC-3' and 5'TTCTGAGCTGGCACAGTGA-3'; $\alpha$ Sma, $5^{\prime}$-TGATCACCATTGGAAACGAA- $3^{\prime}$ and $5^{\prime}$-CCCTGACAGGACGTTGTTA-3'; Tgfbl, $5^{\prime}$-ATTCAGCGCTCACTGCTCTT-3' and 5'-GTTGGTATCCAGGGCTCTCC-3'; Timp1, 5'-TCCCCAGAAATCAACGAGAC- $3^{\prime}$ and $5^{\prime}$-TGGGACTTGTGGGCATATC- $3^{\prime}$; and $T n f \alpha, 5^{\prime}$-CGAGTGACAAGCCTGTAGCC- $3^{\prime}$ and $5^{\prime}$-CTTGTCCCTTGAAGAGAACC- $3^{\prime}$.

\section{Statistical Analysis}

Results are means \pm SEM of at least three independent experiments. Statistical significance was assessed using a two-tailed $t$-test, with $P<0.05$ considered significant.

A

3d

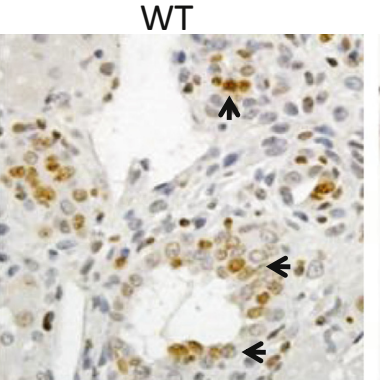

7d

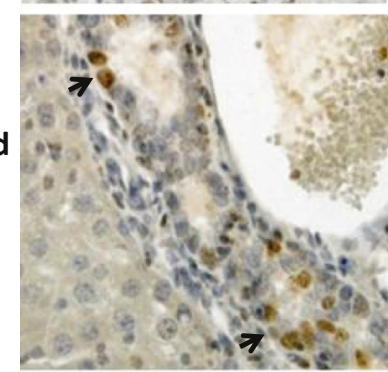

$14 d$
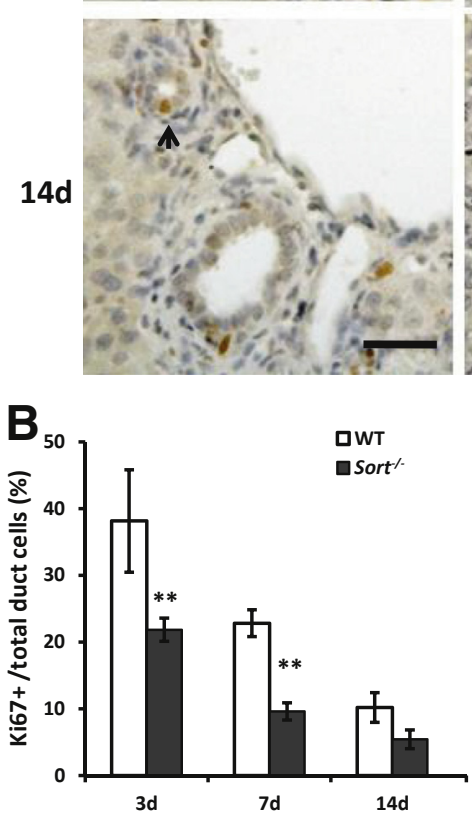
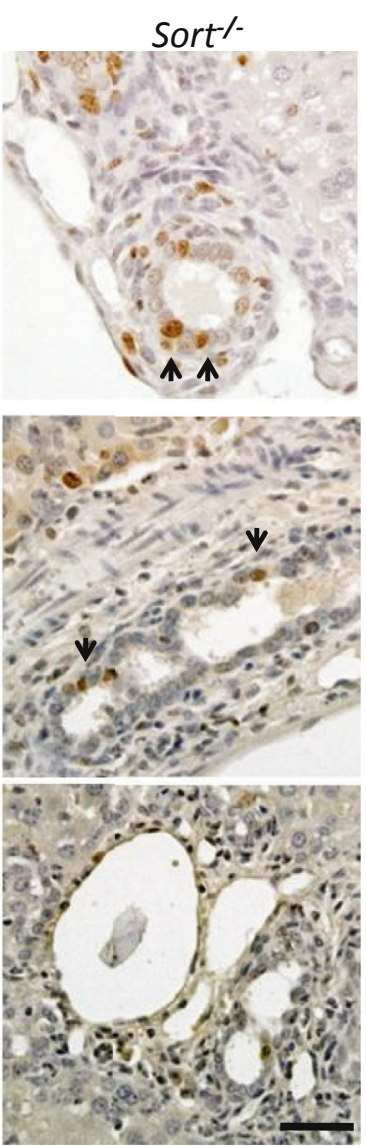

C

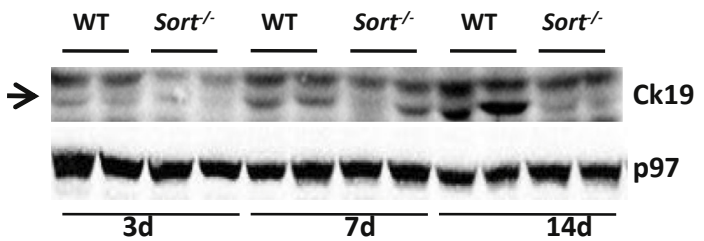

\section{Results}

Sortilin $^{-/-}$Mice Display Reduced Cholangiocyte

Proliferation, Reduced Reactive Cholangiocyte-Derived Cytokines and Chemokines, and Reduced Inflammation 3 Days after BDL

In the early stages after BDL, cholangiocytes proliferate and become reactive, then differentiate and form new bile ducts, a phenomenon termed ductular reaction when accompanied by fibrosis and inflammation. ${ }^{3,6,7}$ Previous studies have shown two peaks of cholangiocyte proliferation after BDL, 2 to 3 days and 5 days after. ${ }^{34}$ Although WT mice display strong proliferation of cells forming bile ducts, as assessed by staining for $\mathrm{Ki}-67$, peaking at 3 days after BDL, Sortilin $^{-1-}$ show significantly reduced numbers of Ki- $67^{+}$

Figure 1 Sortilin ${ }^{-/-}$mice have attenuated cholangiocyte proliferation. A: Immunohistochemical staining for $\mathrm{Ki}-67$ in livers of wild-type (WT) and Sortilin ${ }^{-/}\left(\right.$Sort $\left.^{-/-}\right)$mice 3, 7, and 14 days after bile duct ligation (BDL); the arrows show positively stained cholangiocytes (brown) present in newly formed bile ducts. B: Quantitation of Ki67-positive cells in WT and Sortilin ${ }^{-1-}$ mice. C: Western blot showing expression of cytokeratin (CK) 19 in livers of WT and Sortilin ${ }^{-/-}$mice 3, 7, and 14 days after BDL. Arrow indicates the CK19 specific band. D: Expression of cholangiocyte mitogens (Prgn and $\mathrm{Ngf}$ ) is reduced in Sortilin $^{-/-}$mice 3 days after BDL. Expression of the markers was assessed by real-time quantitative RT-PCR and normalized to expression of Rplpo. Results are expressed as means \pm SEM (B and $\mathbf{D}$ ). $n=1$ slide for each condition (A); $n=3$ slides for each condition (B); $n=2$ slides for each condition (C); $n=5$ to 8 slides for each condition (D). ${ }^{\star} P<0.05,{ }^{*} P<0.01$. Scale bars $=100 \mu \mathrm{m}(\mathbf{A})$. 
cells in bile ducts both 3 days and 7 days after BDL (Figure 1, A and B). The reduced number of cytokeratin $19^{+}$ cholangiocytes in Sortilin ${ }^{-1-}$ was also observed in Western blot analysis, where liver extracts from Sortilin ${ }^{-1-}$ displayed reduced expression of cytokeratin 19, particularly at 14 days after BDL (Figure 1C). In addition, mRNA expression of cholangiocyte autocrine factors and mitogens, including progranulin and nerve growth factor, were significantly reduced in Sortilin ${ }^{-1-}$ mice 3 days after BDL (Figure 1D). Sortilin is known to bind serum progranulin and internalize it for degradation. ${ }^{35}$ Indeed, Sortilin ${ }^{-1-}$ mice had strongly increased serum levels of progranulin (Supplemental Figure S1), which in the absence of neutrophil-derived proteases and elastase, remains in its anti-inflammatory, uncleaved form. ${ }^{36}$

Sortilin $^{-1-}$ mice also displayed significantly attenuated expression of reactive cholangiocyte-derived cytokines and chemokines, with a reduction of hepatic Il-6, Tnf $\alpha$, and $C c l 2$ and the neutrophil recruitment chemokines $\mathrm{Cxcll}$ and $\mathrm{Cxcl} 2$ 3 days after BDL (Figure 2A). The monocyte recruitment chemokine $C c l 2$ was significantly reduced at 3,7 , and 14 days after BDL in Sortilin ${ }^{-1-}$ mice (Figure 2A). Neutrophil accumulation takes place 8 hours to 3 days after BDL. ${ }^{34} \mathrm{We}$ further confirmed the inflammatory response by immunohistochemistry for the neutrophil marker Ly6G, showing the presence of neutrophils near the portal spaces and bile ducts
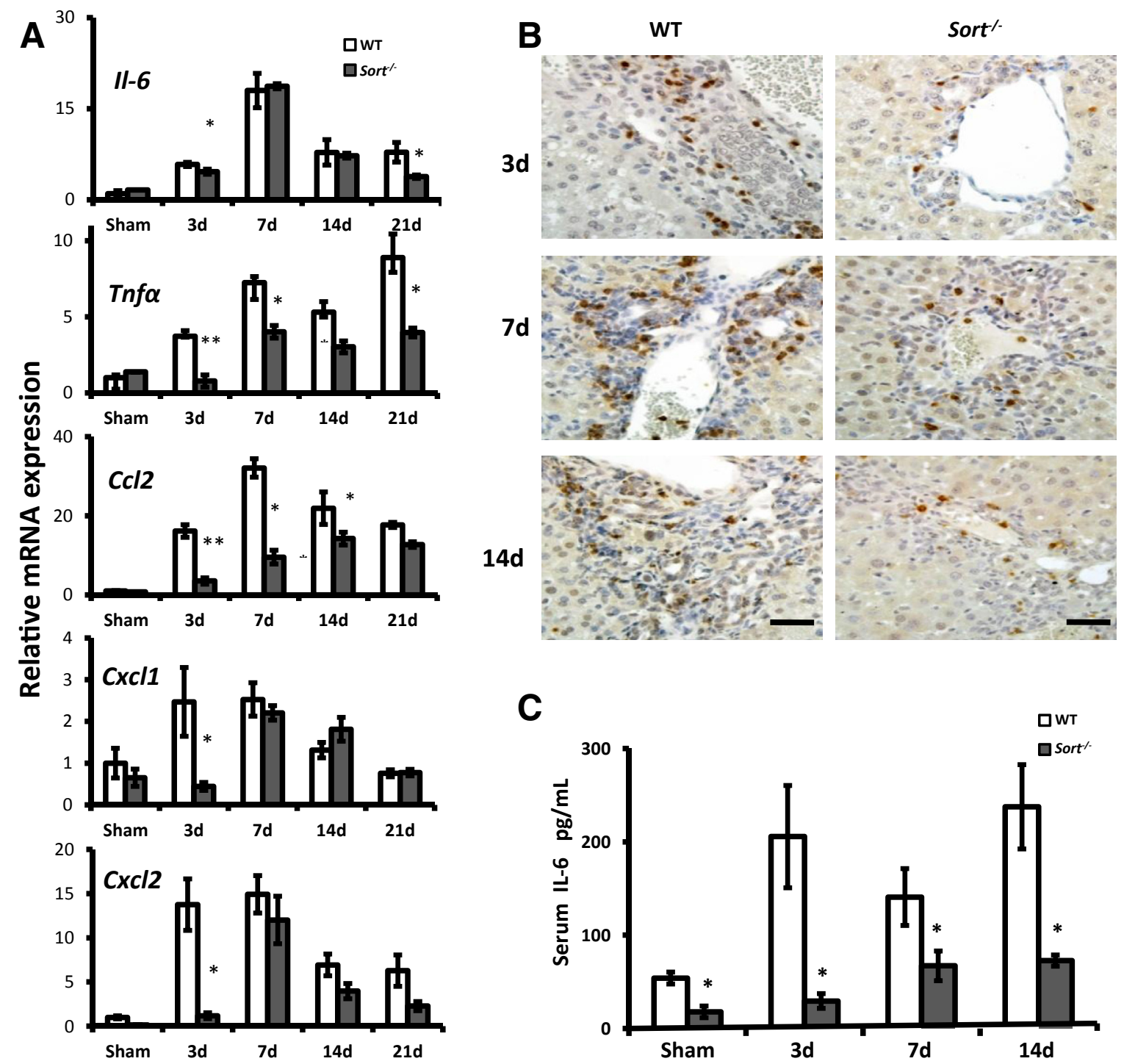

Figure 2 Sortilin ${ }^{-/-}\left(\right.$Sort $\left.^{-/-}\right)$mice have attenuated expression of reactive cholangiocyte-derived cytokines and chemokines and reduced inflammation after bile duct ligation (BDL). A: Expression of reactive cholangiocyte-derived cytokines and chemokines in wild-type (WT) and Sortilin ${ }^{-/-}$mice. Expression of the cytokines was assessed by real-time quantitative RT-PCR and normalized to expression of Rplpo. B: Immunohistochemical staining with an antibody for Ly6G shows reduced neutrophil infiltration in liver of Sortilin ${ }^{-/-}$mice 3, 7, and 14 days after BDL. C: Levels of serum IL-6 in WT and Sortilin ${ }^{-/-}$mice subjected to sham operations or BDL. Results are of IL- 6 determined by enzyme-linked immunosorbent assay. Results are expressed as means \pm SEM (A and $\mathbf{C})$. $n=5$ to $8(\mathbf{A}) ; n=5$ (C). ${ }^{*} P<0.05,{ }^{* *} P<0.01$. Scale bars $=100 \mu \mathrm{m}(\mathbf{B})$. 
in WT mice (Figure 2B). Neutrophil presence was almost undetectable in Sortilin $^{-1-}$ mice 3 days after BDL (Figure 2B).

Previous studies reported that sortilin regulated IL-6 secretion from secretory vesicles and attenuated serum IL-6 levels in atherosclerosis. ${ }^{13}$ As expected, Sortilin ${ }^{-1-}$ mice displayed significantly reduced serum IL-6 in sham mice and 3, 7, and 14 days after BDL (Figure 2C). In addition, liver extracts of Sortilin ${ }^{-1-}$ mice after BDL showed reduced expression of IL-6, TNF- $\alpha$, and interferon- $\gamma$, particularly 3 and 7 days after BDL (Supplemental Figure S2).

\section{Sortilin $^{-/-}$Mice Have Reduced Hepatic Fibrosis after BDL and Attenuated Activation Phenotype of HSCs in Vitro}

Serum levels of hepatic enzymes are increased 2 days after BDL, which is the starting point for development of chronic injury and repair process from 7 to 14 days. ${ }^{34}$ Indeed, serum levels of aspartate aminotransferase, alkaline phosphatase, and total serum bile acids, but not alanine aminotransferase, were significantly lower in Sortilin $^{-1-}$ mice 3 days after $\mathrm{BDL}$, as compared to WT mice (Figure 3A), indicating reduced hepatocellular and cholestatic damage. Bile acids induce oxidative stress, resulting in hepatocyte apoptosis, ${ }^{37}$ and measurement of hepatic oxidative stress by thiobarbituric acid reactive substances showed that Sortilin $^{-1-}$ mice displayed reduced oxidative stress 3 days after BDL (Supplemental Figure S3).

The reduction in serum total bile acids of Sortilin ${ }^{-1-}$ mice 3 days after BDL (Figure 3A) was accompanied by a slight reduction of the bile acids transporter $A b c b 11$ at 3 days after BDL (Supplemental Figure S4), indicating reduced hepatic levels of bile acids, because bile acids increase transcription of $A b c b 11$ via their nuclear receptor FXR. ${ }^{38}$

The reduced inflammation and liver damage led us to further investigate the final and chronic stage of liver damage and repair, namely fibrosis. Indeed, Sortilin ${ }^{-1-}$ mice displayed a dramatic reduction of hepatic fibrosis 14
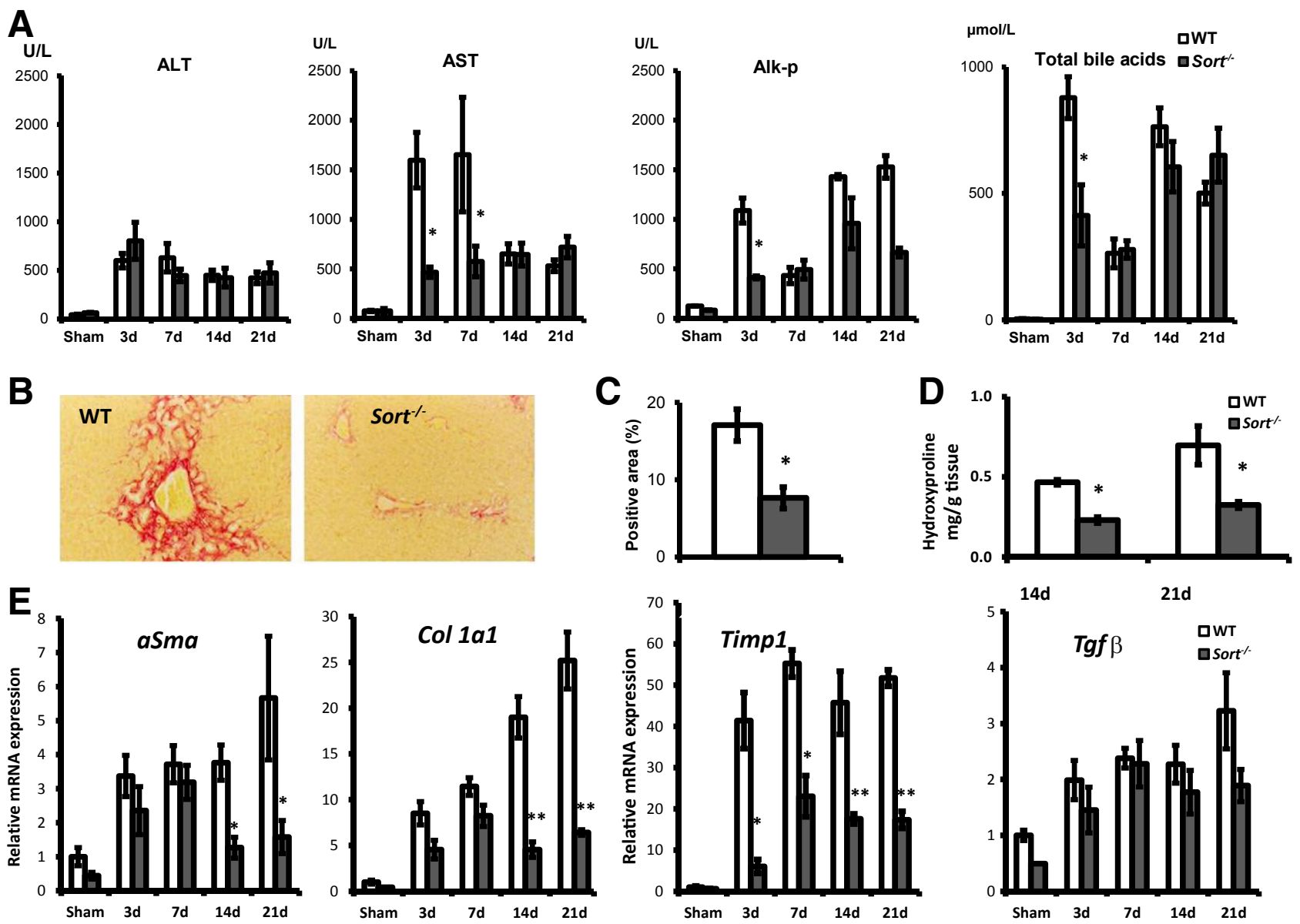

Figure 3 Sortilin ${ }^{-/-}\left(\right.$Sort $\left.^{-/-}\right)$mice display reduced hepatic damage and fibrosis after bile duct ligation (BDL). A: Serum levels of alanine aminotransferase (ALT), aspartate aminotransferase (AST), alkaline phosphatase (Alk P), and total bile acids in wild-type (WT) and Sortilin ${ }^{-1-}$ mice 3, 7, and 14 days after BDL. B: Liver sections showing Sirius Red staining in WT and Sortilin ${ }^{-1-}$ mice 14 days after BDL. C: Quantitation of the Sirius Red-positive areas determined using ImageJ. D: Hydroxyproline levels. E: Expression of fibrogenic markers col1 $\alpha 1, \alpha$ Sma, Timp1, and Tgf $\beta$ in livers of WT and Sortilin ${ }^{-1-}$ mice 14 and 21 days after BDL. Results are expressed as means $\pm \operatorname{SEM}(\mathbf{A}$ and $\mathbf{C}-\mathbf{E}) . n=5(\mathbf{A}, \mathbf{C}$, and $\mathbf{D}) ; n=5$ to $8(\mathbf{E}) .{ }^{*} P<0.05, * * P<0.01$. Original magnification, $\times 10(\mathbf{B})$. $\mathrm{U}$, units. 
and 21 days after BDL (Figure 3, B-E). Hydroxyproline levels were significantly reduced at 14 and 21 days after BDL and, in accordance, expression of fibrogenic markers, $\alpha$ Sma, Coll $\alpha 1$, and Timp1, was also significantly reduced in Sortilin $^{-1-}$ mice at 14 and 21 days after BDL (Figure 3E). There was no significant reduction of $T g f \beta$ mRNA levels in Sortilin $^{-1-}$ mice (Figure 3E).

To assess whether sortilin deficiency had a protective effect in other fibrosis models, we established an additional fibrosis model, using carbon tetrachloride administration for 4 weeks. Liver damage was attenuated in Sortilin ${ }^{-1-}$ mice after carbon tetrachloride, as demonstrated by significantly lower serum alanine aminotransferase and aspartate aminotransferase levels (Figure 4A). As in the BDL model, Sortilin $^{-1-}$ mice displayed reduced fibrosis, as determined by quantitation of Sirius Red-positive areas (Figure 4, $\mathrm{B}$ and C). Sortilin ${ }^{-1-}$ mice also displayed significantly reduced levels of hydroxyproline in the carbon tetrachloride model (Figure 4D). Analysis of fibrogenic genes revealed that only Timpl was significantly reduced in Sortilin ${ }^{-1-}$ mice, whereas levels of $\alpha \mathrm{Sma}$ and Coll $\alpha \mathrm{l}$ were similar to those of WT mice (Figure 4E).

We next investigated the phenotype of HSCs isolated from WT and Sortilin ${ }^{-1-}$ mice. HSCs were isolated and cultured in vitro for 7 and 14 days, allowing them to reach an activated and fully activated phenotype, respectively. Western blot analysis of activation markers for HSC (collagen I, $\alpha$-smooth muscle actin, and platelet-derived growth factor receptor $\beta$ ) showed a strong reduction in fully activated Sortilin ${ }^{-1-}$ HSCs (Figure 4, F and G).
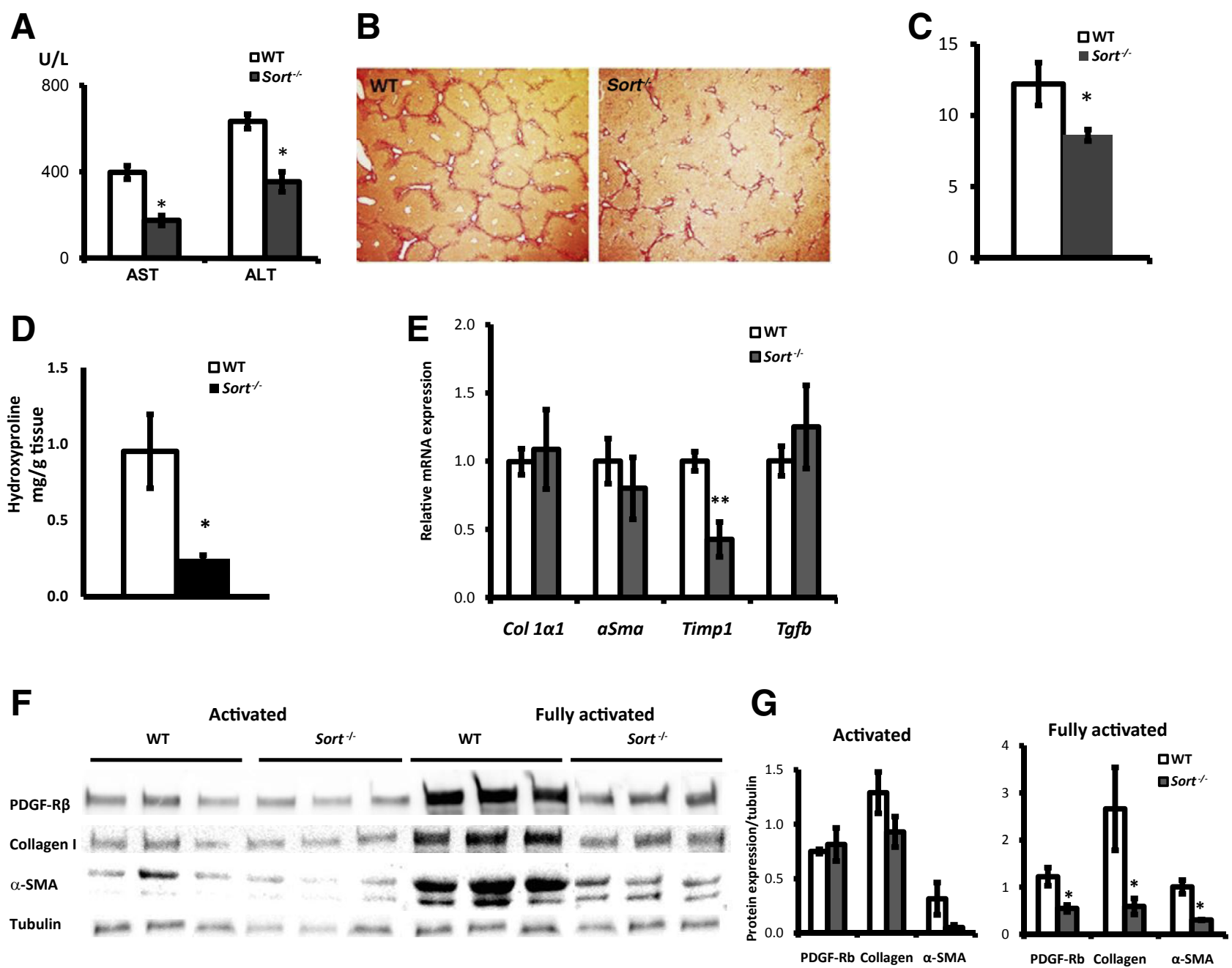

Figure 4 Sortilin $^{-/-}\left(\right.$Sort $\left.^{-/-}\right)$mice display reduced fibrosis after carbon tetrachloride treatment and attenuated hepatic stellate cell (HSC) activation in vitro. A: Serum levels of alanine aminotransferase (ALT) and aspartate aminotransferase (AST) in wild-type (WT) and Sortilin ${ }^{-1-}$ mice after 4 weeks of carbon tetrachloride. B: Liver sections showing Sirius Red staining in WT and Sortilin ${ }^{-/}$mice after carbon tetrachloride administration. C: Quantitation of the Sirius Red-positive areas determined using ImageJ. D: Hydroxyproline levels. E: Expression of fibrogenic markers col1 $\alpha 1, \alpha \operatorname{Sma}$, Timp1, and Tgf $\beta$ in livers of WT and Sortilin ${ }^{-1}$ mice after carbon tetrachloride administration. F: Western blots showing expression of activation markers in activated and fully activated HSCs from WT and Sortilin ${ }^{-1-}$ mice. Each slot is from a different pool of HSCS. Tubulin expression shows protein loading. G: Histogram showing densitometry of activation markers from $\mathbf{F}$, normalized to tubulin expression. Results are expressed as means $\pm \operatorname{SEM}(\mathbf{A}, \mathbf{C}-\mathbf{E}$, and $\mathbf{G}) . n=5(\mathbf{A}, \mathbf{C}$, and $\mathbf{D}) ; n=5$ to $8(\mathbf{E}) ; n=3(\mathbf{F}$ and G). ${ }^{*} P<0.05,{ }^{*} P<0.01$. Original magnification, $\times 10$ (B). PDGFR, platelet-derived growth factor receptor; $\alpha$-SMA, $\alpha$-smooth muscle actin. 
Sortilin $^{-/-}$Mice Have Reduced aSMase Activity Accompanied by Reduced Hepatic Apoptosis in Vivo after BDL

Our previous studies demonstrated that Sortilin ${ }^{-1-}$ mice have reduced hepatic and adipose tissue aSMase activity after a high-fat diet, where this reduced aSMase activity reduced insulin resistance, because ceramide inhibits insulin signaling. ${ }^{30}$ Reduced aSMase activity results in lower levels of ceramide and attenuates apoptosis in many cell types. $^{27,39,40}$ Therefore, we hypothesized that reduced aSMase activity might be responsible, at least in part, for the attenuated damage, inflammation, and fibrosis in sortilin ${ }^{-/-}$ mice. A significant reduction in aSMase activity was observed in Sortilin ${ }^{-1-}$ mice 7 days after BDL treatment (Figure 5A). Moreover, aSMase activity was also reduced in livers of Sortilin ${ }^{-1-}$ mice after carbon tetrachloride administration (Figure 5B).
To determine the extent of aSMase inhibition after in vivo administration of the aSMase inhibitor amitriptyline to WT mice after BDL, we performed aSMase activity assays. Amitriptyline reduced aSMase activity by $30 \% 7$ days after BDL and 50\% 14 days after BDL (Figure 5C).

Next, we investigated whether the reduced aSMase activity was associated with reduced hepatic apoptosis and, indeed, although WT mice showed hepatic apoptosis 7 days after BDL, there was no detectable apoptosis in Sortilin $^{-1-}$ livers (Figure 5D). We did not observe apoptosis 3 days after BDL (data not shown). Moreover, pharmacological inhibition of aSMase with amitriptyline in WT after BDL also resulted in abolition of liver apoptosis (Figure 5D). A similar reduction in hepatic apoptosis in Sortilin $^{-1-}$ mice was observed 14 days after BDL (Figure 5E) and after carbon tetrachloride treatment (Figure 5F).
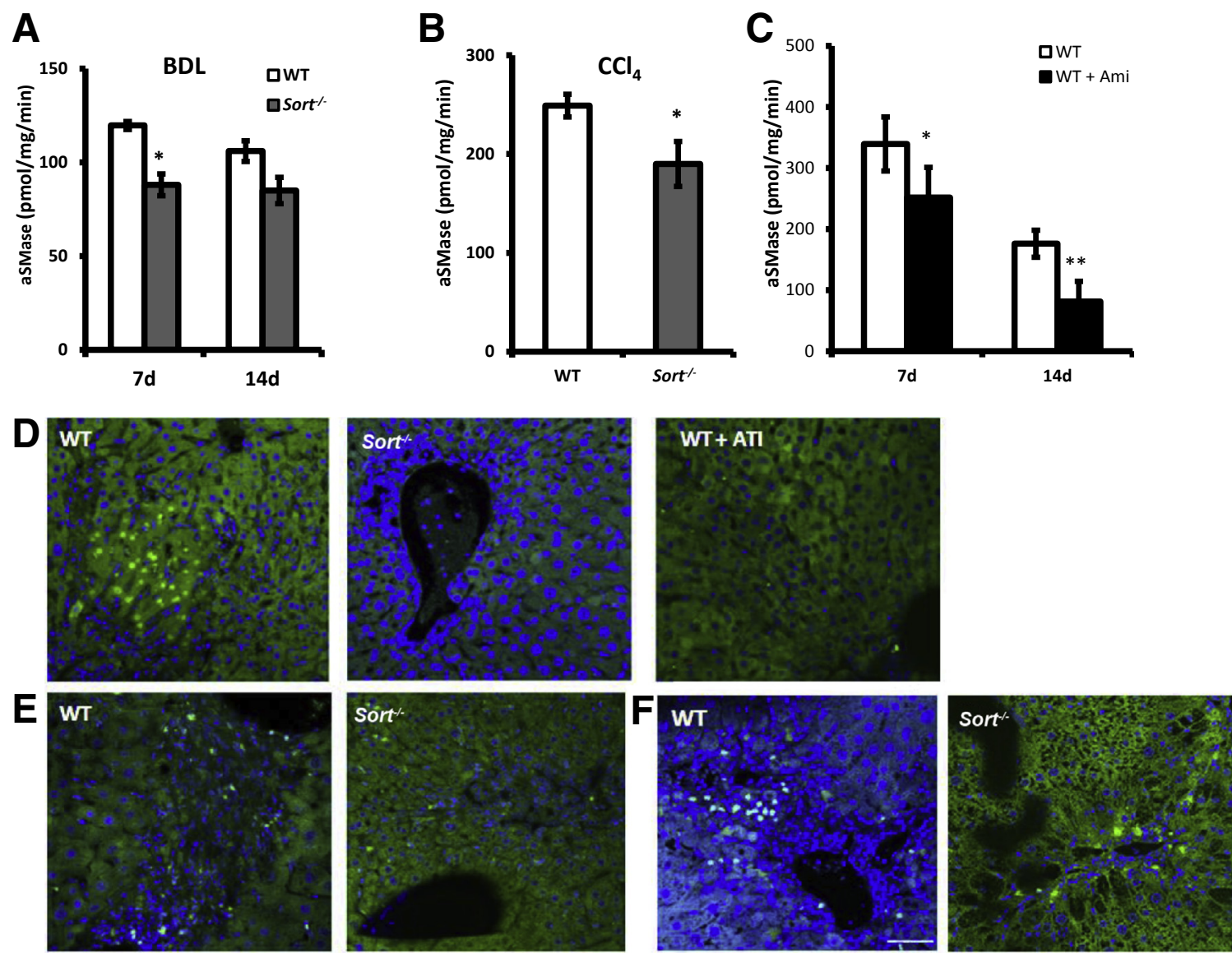

Figure 5 aSMase activity is reduced in Sortilin ${ }^{-/-}\left(\right.$Sort $\left.^{-/-}\right)$mice after bile duct ligation (BDL) and carbon tetrachloride and accompanied by reduced liver apoptosis. A: aSMase activity was measured in liver homogenates (40 to $50 \mu \mathrm{g}$ of protein) of wild-type (WT) and Sortilin ${ }^{-/}$mice 7 and 14 days after BDL. B: aSMase activity was measured in liver homogenates (40 to $50 \mu \mathrm{g}$ of protein) of WT and Sortilin ${ }^{-1-}$ mice 4 weeks after carbon tetrachloride administration. C: aSMase activity was measured in liver homogenates (40 to $50 \mu \mathrm{g}$ of protein) of WT mice that were treated daily with amitriptyline for 7 and 14 days after BDL. D: Terminal deoxynucleotidyl transferase-mediated dUTP nick-end labeling (TUNEL) assay showing apoptosis in WT, but not in Sortilin ${ }^{-/-}$mice, 7 days after BDL. Pharmacological inhibition of aSMase with amitriptyline in WT mice after BDL attenuates apoptosis. E: TUNEL assay showing apoptosis in WT and Sortilin $^{-/-}$mice 14 days after BDL. F: TUNEL assay showing apoptosis in WT and Sortilin ${ }^{-/-}$mice after 4 weeks of carbon tetrachloride. Results are expressed as means \pm SEM $(\mathbf{A})$ or means \pm SEM (each performed in duplicate; $\mathbf{B}$ and $\mathbf{C}$ ). $n=3$ to $5(\mathbf{A}) ; n=3(\mathbf{B}$ and $\mathbf{C})$. ${ }^{\star} P<0.05,{ }^{* *} P<0.01$. Scale bar $=100 \mu \mathrm{m}$ $(\mathbf{D}-\mathbf{F})$. 

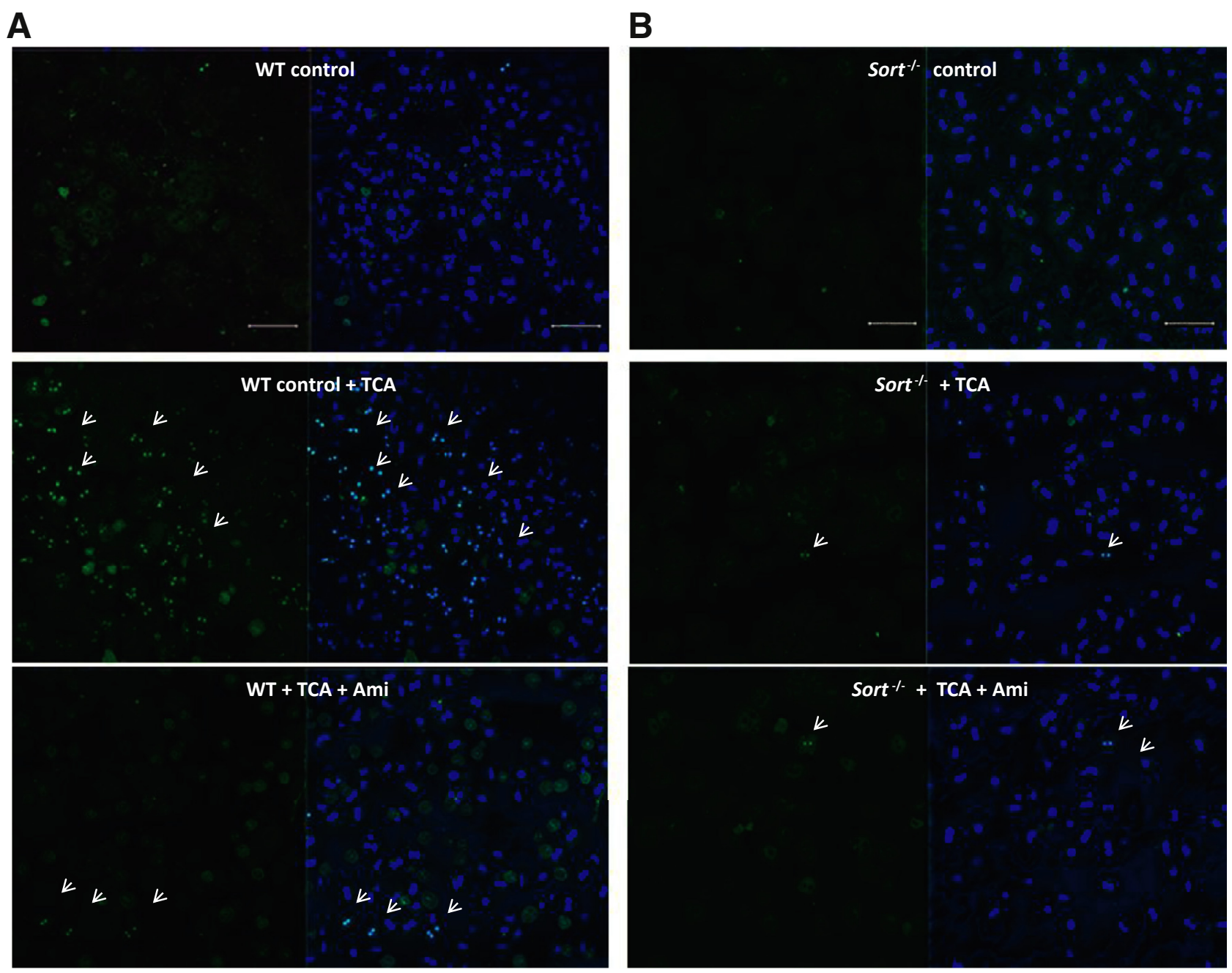

Figure 6 Sortilin ${ }^{-/-}\left(\right.$Sort $\left.^{-/-}\right)$hepatocytes are less susceptible to bile acid induction of apoptosis. Wild-type (WT) and Sortilin ${ }^{-/-}$hepatocytes were isolated and plated on collagen I-coated plates, then treated the next day for 8 hours with $200 \mu \mathrm{mol} / \mathrm{L}$ taurocholic acid (TCA), in the presence or absence of $10 \mu \mathrm{mol} / \mathrm{L}$ amitriptyline, to inhibit aSMase activity. Apoptosis was assessed using a terminal deoxynucleotidyl transferase-mediated dUTP nick-end labeling (TUNEL) assay. A: WT hepatocytes. B: Sortilin ${ }^{-1-}$ hepatocytes. The left column shows apoptotic hepatocytes stained green, and the right column shows double-stained nuclei for DAPI (blue) and for both TUNEL and DAPI (bright light blue). The arrows show apoptotic hepatocytes. Scale bars $=100 \mu \mathrm{m}(\mathbf{A}$ and $\mathbf{B})$.

\section{Sortilin ${ }^{-/-}$Hepatocytes Have Reduced in Vitro Apoptosis in Response to Bile Acids}

To further decipher the involvement of aSMase in cholestatic injury, we determined the susceptibility of Sortilin ${ }^{-1-}$ hepatocytes to bile acid-induced necrosis/apoptosis. We assessed apoptosis in response to one of the main bile acids whose levels are increased after BDL, namely TCA. ${ }^{41}$ We observed strong apoptosis induction in WT hepatocytes in response to TCA treatment, which was abolished in the presence of the pharmacological aSMase inhibitor amitriptyline (Figure 6A). In line with our hypothesis, there was almost no apoptosis induction in Sortilin $^{-/-}$hepatocytes treated with TCA (Figure 6B). These results indicate that TCA induces hepatocyte apoptosis by an aSMase-dependent mechanism.

\section{Although Short-Term IL-6 Neutralization Reduces Inflammation and Ductular Reaction at Early Stages after BDL, Only Combined Inhibition of IL- 6 and aSMase Reduces Fibrosis}

To investigate whether reduced IL- 6 played a role in reduced expression of reactive cholangiocyte cytokines and in attenuated inflammation in the Sortilin ${ }^{-1-}$ mice in early stages after BDL, we treated WT with a neutralizing antibody to IL-6, after being subjected to BDL. Indeed, we detected significantly reduced mRNA expression for reactive cholangiocyte-derived cytokines and growth factors, including $\mathrm{Il}-6, \mathrm{Ccl} 2, \mathrm{Ng}$, and $\mathrm{Cxcll}$ (Figure 7A). However, neutralization of IL-6 did not affect expression of fibrosis markers (Supplemental Figure S5). 

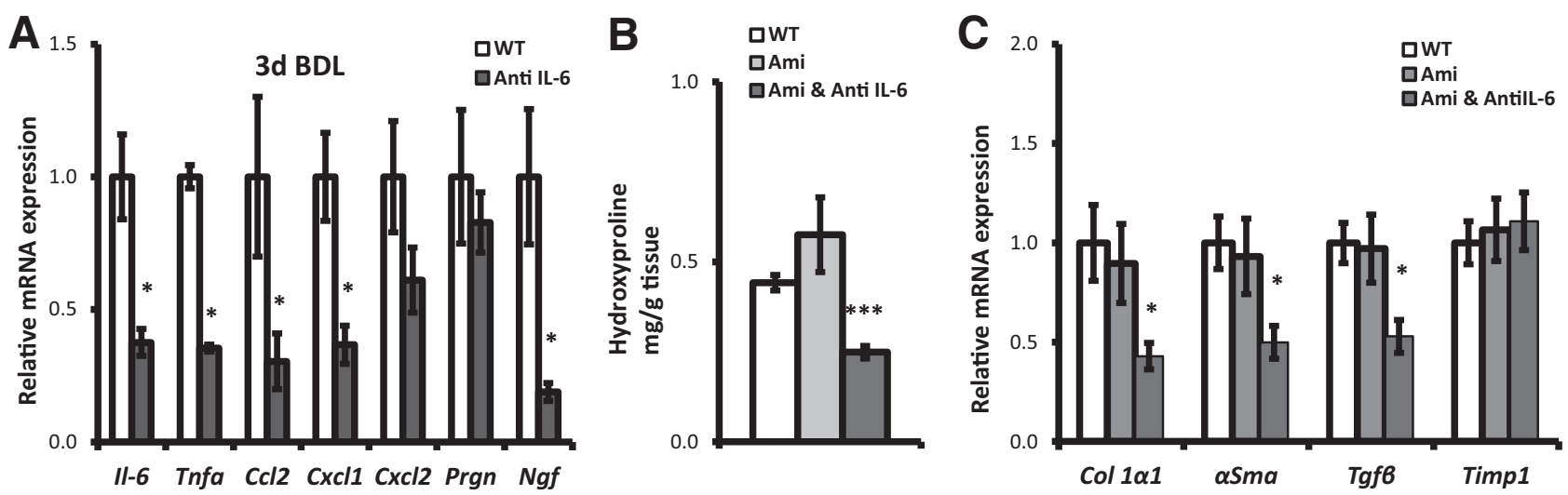

Figure 7 Only combined inhibition of both IL-6 and aSMase leads to reduced fibrosis after bile duct ligation (BDL). A: Neutralization of IL-6 reduces inflammation at 3 days after BDL. Expression of reactive cholangiocyte-derived mitogens, cytokines, and chemokines is reduced 3 days after BDL in wild-type (WT) mice that received daily injections of anti-IL-6 antibody. Expression was assessed by quantitative RT-PCR (RT-qPCR) and normalized to expression of Rplpo. B: Treatment with anti-IL-6 and amitriptyline (ami) reduced hydroxyproline after BDL. Hydroxyproline levels of WT mice after BDL that received either daily injections of amitriptyline or a combined treatment of anti-IL-6 for 3 days and daily amitriptyline. All mice were sacrificed 14 days after BDL. C: Treatment with anti-IL-6 and amitriptyline reduced expression of fibrogenic markers after BDL. WT mice were bile duct ligated and treated with amitriptyline alone or with anti-IL- 6 and amitriptyline. Expression of the fibrogenic markers was assessed by RT-qPCR. Results are expressed as means \pm SEM $(\mathbf{A}-\mathbf{C}) . n=5$ to $8(\mathbf{A}) ; n=5$ (B and $\mathbf{C}) .{ }^{*} P<0.05, * * * P<0.005$.

We next determined whether pharmacological inhibition of aSMase by amitriptyline treatment affected liver fibrosis in the BDL model. Amitriptyline inhibition of aSMase proved insufficient to affect hepatic fibrosis, as determined by expression of fibrogenic markers and hydroxyproline levels (Figure 7, B and C), yet induced expression of inflammatory cytokines and chemokines (Supplemental Figure S5).

Because anti-IL-6 reduces inflammation, we hypothesized that attenuation of inflammation, together with attenuation of hepatocyte apoptosis by aSMase inhibition, may act to reduce fibrosis. To test this hypothesis, we treated bile duct-ligated mice with anti-IL-6 for 3 days together with daily administration of amitriptyline for 14 days. This treatment resulted in significantly reduced hydroxyproline (Figure 7B), accompanied by significantly reduced expression of fibrogenic markers (Figure 7C).

\section{Discussion}

In the current study, we describe a previously unidentified and distinct role for sortilin in the pathogenesis of biliary fibrosis/cirrhosis. We attribute the attenuated inflammation, ductular reaction, and fibrosis in Sortilin ${ }^{-1-}$ mice to the combined effects of reduced aSMase activity and IL-6 levels in these mice. Sortilin ${ }^{-1-}$ mice have continuously reduced serum IL-6 levels after BDL, accompanied by reduced cholangiocyte proliferation, reduced formation of reactive cholangiocytes, and reduced hepatic inflammation. Shortterm neutralization of IL-6 after BDL treatment mimics the effect of sortilin deficiency with respect to the expression of reactive cholangiocyte-derived cytokines and chemokines. In addition, we observed attenuated bile acid-induced apoptosis in Sortilin ${ }^{-1-}$ hepatocytes in vitro, and in vivo after BDL and carbon tetrachloride, which we ascribe to reduced aSMase activity in Sortilin ${ }^{-1-}$ hepatocytes. However, pharmacological inhibition of aSMase after BDL, despite reducing hepatocyte apoptosis, was not sufficient to attenuate inflammation and fibrosis. We found that only combined inhibition of both Il- 6 and aSMase mimicked the antifibrotic effect of sortilin in the BDL model.

Sortilin is a newly identified member of the vacuolar protein sorting 10 family, playing a role both as a coreceptor and as a trafficking molecule in the trans-Golgi network. ${ }^{11}$ One of the enzymes trafficked by sortilin is aSMase, an enzyme whose role in regulation of cellular apoptosis has been demonstrated in several cell types. For example, antidepressant drugs (imipramine and amitriptyline) act via inhibition of aSMase activity, leading to reduced ceramide levels in the hippocampus and increased neuronal survival, proliferation, and maturation. ${ }^{39}$ In Wilson disease, pharmacological inhibition of aSMase attenuates $\mathrm{Cu}^{++}$-induced hepatocyte apoptosis. ${ }^{40}$ In addition, hepatocytes from Asmase $^{-1-}$ mice display reduced apoptosis in response to TNF- $\alpha .{ }^{27}$ In line with these previous studies, we demonstrated reduced hepatic aSMase activity in Sortilin ${ }^{-1-}$ mice in the BDL and carbon tetrachloride models, accompanied by reduced hepatic apoptosis.

In the liver, partial aSMase inhibition has a beneficial role in hepatic fibrosis, because heterozygous ssmase $^{+/-}$mice show reduced hepatic fibrosis after BDL or carbon tetrachloride treatment, ${ }^{28,29}$ whereas total aSMase deletion (in Asmase $^{-1-}$ mice) is deleterious and results in increased liver fibrosis, perhaps because of increased cathepsin B expression. ${ }^{29}$ Therefore, partial inhibition of aSMase in the liver of Sortilin $^{-/-}$mice may be protective in fibrosis models. Partial inhibition of aSMase in Asmase $e^{+/-}$-derived HSCs was also 
responsible for the attenuated activation of these cells ${ }^{28}$ and may explain the attenuated phenotype of HSCs derived from Sortilin $^{-1-}$ mice in our studies. In other models of liver damage (eg, in alcohol-induced liver damage and fibrosis), aSMase was required for induction of endoplasmic reticulum stress $^{42}$ and pharmacological inhibition of aSMase with imipramine had a beneficial effect. ${ }^{43}$ Recently, aSMase has been suggested to play a role in the transition from steatosis to steatohepatitis, because aSMase activation is necessary for endoplasmic reticulum stress induction, autophagy, and lysosomal membrane permeabilization, leading to hepatic lipotoxicity. ${ }^{44,45}$ Our previous studies have also shown that Sortilin $^{-1-}$ mice displayed strongly attenuated hepatic inflammation and steatosis and improved insulin sensitivity because of reduced aSMase activity in both liver and visceral adipose tissue of high-fat diet-fed mice. ${ }^{30}$ In the present study, we observed that in vivo administration of amitriptyline to WT mice after BDL, despite reducing hepatocyte apoptosis, did not significantly reduce fibrosis or inflammation, suggesting that the beneficial effect of sortilin deficiency was not solely mediated via reduced aSMase activity.

One of the characteristics of cholangiopathies, conditions in which bile ducts are primary targets of injury, such as primary biliary cirrhosis and primary sclerosing cholangitis, is increased numbers of proliferating bile ducts, often associated with an influx of inflammatory cells, a phenomenon termed the ductular reaction. The proliferating bile duct cells become reactive cholangiocytes and express increased levels of specific cytokines, growth factors, adhesion molecules, and fibrogenic stimuli, which lead to activation of HSCs and development of fibrosis. ${ }^{3,6,7}$ The present study has shown both reduced cholangiocyte proliferation and reduced expression of reactive cholangiocyte-derived factors (Il-6, Tnf $\alpha, C c l 2$, Cxcll, Cxcl2, and Ngf) in Sortilin ${ }^{-1-}$ mice 3 days after BDL.

Sortilin is responsible for the secretion of IL-6 from secretory vesicles, and as a result, mice reconstituted with Sortilin $^{-1-}$ bone marrow display reduced circulating serum IL- $6 .{ }^{13}$ In line with these findings, our studies have shown significantly lower mRNA expression of IL-6 in Sortilin ${ }^{-1-}$ at the peak of inflammation at 3 days after BDL, as well as lower serum IL-6 in Sortilin ${ }^{-1-}$ mice sham operated or at all time points after BDL. Previous studies implicated IL- 6 as a major mitogen for cholangiocytes, via either pSTAT3 or perk1/erk2 signaling. ${ }^{16-18}$ However, more recent studies have shown that IL-6 may exacerbate cholestatic liver injury. ${ }^{20,21}$ Our studies showed that short-term IL-6 neutralization lead to reduced expression of reactive cholangiocyte-derived cytokines, suggesting a role for IL-6 in induction of the reactive cholangiocyte phenotype.

In conclusion, we have described a novel role for sortilin in cholestatic liver injury, where sortilin deficiency via two different mechanisms contributes to attenuated inflammation, ductular reaction, hepatocyte apoptosis, and liver fibrosis.

\section{Acknowledgments}

We thank Dr. Alex Litvak, head of our Animal Institute, and Dr. Michael Kaplan for their help with our animal studies.

Authors contributions: E.H., A.S., J.A.D., O.S., and I.Z. participated in study design and data interpretation; E.H., A.S., W.-J.P., E.G.L., W.-J.P., and I.Z. participated in data collection; E.H., Y.P.J., A.H.F., J.A.D., S.F., O.S., and I.Z. participated in the writing of the manuscript; and E.H., A.S., J.A.D., O.S., S.F., R.B., Y.P.J., A.H.F., and I.Z. critically assessed the manuscript.

\section{Supplemental Data}

Supplemental material for this article can be found at http://dx.doi.org/10.1016/j.ajpath.2016.09.005.

\section{References}

1. Friedman SL: Mechanisms of hepatic fibrogenesis. Gastroenterology 2008, 134:1655-1669

2. Bataller R, Brenner DA: Liver fibrosis. J Clin Invest 2005, 115 209-218

3. Penz-Österreicher M, Österreicher CH, Trauner M: Fibrosis in autoimmune and cholestatic liver disease. Best Pract Res Clin Gastroenterol 2011, 25:245-258

4. Fausther M, Lavoie EG, Dranoff JA: Contribution of myofibroblasts of different origins to liver fibrosis. Curr Pathobiol Rep 2013, 1:225-230

5. Mederacke I, Hsu CC, Troeger JS, Huebener P, Mu X, Dapito DH, Pradere JP, Schwabe RF: Fate tracing reveals hepatic stellate cells as dominant contributors to liver fibrosis independent of its aetiology. Nat Commun 2013, 4:2823

6. Hirschfield GM, Heathcote EJ, Gershwin ME: Pathogenesis of cholestatic liver disease and therapeutic approaches. Gastroenterology 2010, 139:1481-1496

7. Syal G, Fausther M, Dranoff JA: Advances in cholangiocyte immunobiology. Am J Physiol Gastrointest Liver Physiol 2012, 303 : G1077-G1086

8. Alvaro D, Mancino MG, Glaser S, Gaudio E, Marzioni M, Francis H, Alpini G: Proliferating cholangiocytes: a neuroendocrine compartment in the diseased liver. Gastroenterology 2007, 132:415-431

9. Jhandier MN, Kruglov EA, Lavoie EG, Sévigny J, Dranoff JA: Portal fibroblasts regulate the proliferation of bile duct epithelia via expression of NTPDase2. J Biol Chem 2005, 280:22986-22992

10. Yu J, Lavoie EG, Sheung N, Tremblay JJ, Sévigny J, Dranoff JA: IL-6 downregulates transcription of NTPDase2 via specific promoter elements. Am J Physiol Gastrointest Liver Physiol 2008, 294:G748-G756

11. Willnow TE, Petersen CM, Nykjaer A: VPS10 P-domain receptors: regulators of neuronal viability and function. Nat Rev Neurosci 2008, 9:899-909

12. Herda S, Raczkowski F, Mittrucker HW, Willimsky G, Gerlach K, Kuh AA, Breiderhoff T, Willnow TE, Dörken B, Höpken UE, Rehm A: The sorting receptor Sortilin exhibits a dual function in exocytic trafficking of interferon- $\gamma$ and granzyme A in T cells. Immunity 2012, 37:854-866

13. Mortensen MB, Kjolby M, Gunnersen S, Larsen JV, Palmfeldt J, Falk ENykjaer A, Bentzon JF: Targeting sortilin in immune cells reduces proinflammatory cytokines and atherosclerosis. J Clin Invest 2014, 124:5317-5322

14. Demetris AJ, Lunz JG 3rd, Specht S, Nozaki I: Biliary wound healing, ductular reactions, and IL-6/gp130 signaling in the development of liver disease. World J Gastroenterol 2006, 12:3512-3522 
15. Liu Z, Sakamoto $\mathrm{T}$, Ezure $\mathrm{T}$, Yokomuro $\mathrm{S}$, Murase $\mathrm{N}$, Michalopoulos G, Poli V, Demetris AJ: Interleukin-6, hepatocyte growth factor, and their receptors in biliary epithelial cells during a type I ductular reaction in mice: interactions between the periductal inflammatory and stromal cells and the biliary epithelium. Hepatology 1998, 28:1260-1268

16. Liu Z, Sakamoto T, Yokomuro S, Ezure T, Subbotin V, Murase N, Contrucci S, Demetris AJ: Acute obstructive cholangiopathy in interleukin-6 deficient mice: compensation by leukemia inhibitory factor (LIF) suggests importance of gp-130 signaling in the ductular reaction. Liver 2000, 20:114-124

17. Park J, Gores GJ, Patel T: Lipopolysaccharide induces cholangiocyte proliferation via an interleukin-6-mediated activation of p44/p42 mitogen-activated protein kinase. Hepatology 1999, 29:1037-1043

18. Xiao Y, Wang J, Yan W, Zhou Y, Chen Y, Zhou K, Wen J, Wang Y, Cai W: Dysregulated miR-124 and miR-200 expression contribute to cholangiocyte proliferation in the cholestatic liver by targeting IL-6/STAT3 signaling. J Hepatol 2015, 62:889-896

19. O'Hara SP, Splinter PL, Trussoni CE, Gajdos GB, Lineswala PN, Larusso NF: Cholangiocyte N-Ras protein mediates lipopolysaccharideinduced interleukin 6 secretion and proliferation. J Biol Chem 2011, 286:30352-30360

20. Zhang W, Tsuda M, Yang GX, Tsuneyama K, Rong G, Ridgway WM, Ansari AA, Flavell RA, Coppel RL, Lian ZX, Gershwin ME: Deletion of interleukin-6 in mice with the dominant negative form of transforming growth factor beta receptor II improves colitis but exacerbates autoimmune cholangitis. Hepatology 2010, 52:215-222

21. Gehring S, Dickson EM, San Martin ME, van Rooijen N, Papa EF, Harty MW, Tracy TF Jr, Gregory SH: Kupffer cells abrogate cholestatic liver injury in mice. Gastroenterology 2006, 30:810-822

22. Wähe A, Kasmapour B, Schmaderer C, Liebl D, Sandhoff K, Nykjaer A, Griffiths G, Gutierrez MG: Golgi-to-phagosome transport of acid sphingomyelinase and prosaposin is mediated by sortilin. J Cell Sci 2010, 123:2502-2511

23. Bao JX, Jin S, Zhang F, Wang ZC, Li N, Li PL: Activation of membrane NADPH oxidase associated with lysosome-targeted acid sphingomyelinase in coronary endothelial cells. Antioxid Redox Signal 2010, 12:703-712

24. Jin S, Yi F, Zhang F, Poklis JL, Li PL: Lysosomal targeting and trafficking of acid sphingomyelinase to lipid raft platforms in coronary endothelial cells. Arterioscler Thromb Vasc Biol 2008, 28:2056-2062

25. Smith EL, Schuchman EH: The unexpected role of acid sphingomyelinase in cell death and the pathophysiology of common diseases. FASEB J 2008, 22:3419-3431

26. Ding WX, Yin XM: Dissection of the multiple mechanisms of TNFalpha-induced apoptosis in liver injury. J Cell Mol Med 2004, 8: 445-454

27. García-Ruiz C, Colell A, Marí M, Morales A, Calvo M, Enrich C, Fernández-Checa JC: Defective TNF-alpha-mediated hepatocellular apoptosis and liver damage in acidic sphingomyelinase knockout mice. J Clin Invest 2003, 111:197-208

28. Moles A, Tarrats N, Morales A, Domínguez M, Bataller R, Caballería J, García-Ruiz C, Fernández-Checa JC, Marí M: Acidic sphingomyelinase controls hepatic stellate cell activation and in vivo liver fibrogenesis. Am J Pathol 2010, 177:1214-1224

29. Moles A, Tarrats N, Fernández-Checa JC, Marí M: Cathepsin B overexpression due to acid sphingomyelinase ablation promotes liver fibrosis in Niemann-Pick disease. J Biol Chem 2012, 287:1178-1188

30. Rabinowich L, Fishman S, Hubel E, Thurm T, Park WJ, Pewzner-Jung Y, Saroha A, Erez N, Halpern Z, Futerman AH, Zvibel I: Sortilin deficiency improves the metabolic phenotype and reduces hepatic steatosis of mice subjected to diet-induced obesity. J Hepatol 2015, 62:175-181

31. Jansen $\mathrm{P}$, Giehl K, Nyengaard JR, Teng K, Lioubinski O, Sjoegaard SS, Gotthardt M, Lin F, Eilers A, Petersen CM, Lewin GR,
Hempstead BL, Willnow TE, Nykjaer A: Roles for the proneurotrophin receptor sortilin in neuronal development, aging and brain injury. Nat Neurosci 2007, 10:1449-1457

32. Puchtler H, Waldrop FS, Valentine LS: Polarization microscopic studies of connective tissue stained with picro-sirius red FBA. Beitr Pathol 1973, 150:174-187

33. Georgiev P, Jochum W, Heinrich S, Jang JH, Nocito A, Dahm F, Clavien PA: Characterization of time-related changes after experimental bile duct ligation. Br J Surg 2008, 95:646-656

34. Futerman AH, Pagano RE: Use of N-([1-14C]hexanoyl) sphingolipids to assay sphingolipid metabolism. Methods Enzymol 1992, 209: 437-446

35. Hu F, Padukkavidana T, Vaegter CB, Brady OA, Zheng Y, Mackenzie IR, Feldman HH, Nykjaer A, Strittmatter SM: Sortilinmediated endocytosis determines levels of the frontotemporal dementia protein, progranulin. Neuron 2010, 68:654-667

36. Kessenbrock K, Fröhlich L, Sixt M, Lämmermann T, Pfister H, Bateman A, Belaaouaj A, Ring J, Ollert M, Fässler R, Jenne DE: Proteinase 3 and neutrophil elastase enhance inflammation in mice by inactivating antiinflammatory progranulin. J Clin Invest 2008, 118:2438-2447

37. Reinehr R, Becker S, Keitel V, Eberle A, Grether-Beck S, Häussinger D: Bile salt-induced apoptosis involves NADPH oxidase isoform activation. Gastroenterology 2005, 129:2009-2031

38. Lefebvre P, Cariou B, Lien F, Kuipers F, Staels B: Role of bile acids and bile acid receptors in metabolic regulation. Physiol Rev 2009, 89: $147-191$

39. Gulbins E, Palmada M, Reichel M, Lüth A, Böhmer C, Amato D, Müller CP, Tischbirek CH, Groemer TW, Tabatabai G, Becker KA, Tripal P, Staedtler S, Ackermann TF, van Brederode J, Alzheimer C, Weller M, Lang UE, Kleuser B, Grassmé H, Kornhuber J: Acid sphingomyelinase-ceramide system mediates effects of antidepressant drugs. Nat Med 2013, 19:934-938

40. Lang PA, Schenck M, Nicolay JP, Becker JU, Kempe DS, Lupescu A, Koka S, Eisele K, Klarl BA, Rübben H, Schmid KW, Mann K, Hildenbrand S, Hefter H, Huber SM, Wieder T, Erhardt A, Häussinger D, Gulbins E, Lang F: Liver cell death and anemia in Wilson disease involve acid sphingomyelinase and ceramide. Nat Med 2007, 13:164-170

41. Zhang Y, Hong JY, Rockwell CE, Copple BL, Jaeschke H, Klaassen CD: Effect of bile duct ligation on bile acid composition in mouse serum and liver. Liver Int 2012, 32:58-69

42. Fernandez A, Matias N, Fucho R, Ribas V, Von Montfort C, Nuño N, Baulies A, Martinez L, Tarrats N, Mari M, Colell A, Morales A, Dubuquoy L, Mathurin P, Bataller R, Caballeria J, Elena M, Balsinde J, Kaplowitz N, Garcia-Ruiz C, Fernandez-Checa JC: ASMase is required for chronic alcohol induced hepatic endoplasmic reticulum stress and mitochondrial cholesterol loading. J Hepatol 2013, 59:805-813

43. Liangpunsakul S, Rahmini Y, Ross RA, Zhao Z, Xu Y, Crabb DW: Imipramine blocks ethanol-induced ASMase activation, ceramide generation, and PP2A activation, and ameliorates hepatic steatosis in ethanol-fed mice. Am J Physiol Gastrointest Liver Physiol 2012, 302: G515-G523

44. Garcia-Ruiz C, Mato JM, Vance D, Kaplowitz N, FernándezCheca JC: Acid sphingomyelinase-ceramide system in steatohepatitis: a novel target regulating multiple pathways. J Hepatol 2015, 62: 219-233

45. Fucho R, Martínez L, Baulies A, Torres S, Tarrats N, Fernandez A, Ribas V, Astudillo AM, Balsinde J, Garcia-Rovés P, Elena M, Bergheim I, Lotersztajn S, Trautwein C, Appelqvist H, Paton AW, Paton JC, Czaja MJ, Kaplowitz N, Fernandez-Checa JC, GarcíaRuiz C: ASMase regulates autophagy and lysosomal membrane permeabilization and its inhibition prevents early stage non-alcoholic steatohepatitis. J Hepatol 2014, 61:1126-1134 